\title{
Application of Airborne Magnetic Survey in Deep Iron Ore Prospecting-A Case Study of Jinling Area in Shandong Province, China
}

\author{
Ning Lu ${ }^{1,2}\left(\mathbb{D}\right.$, Guixiang Liao ${ }^{1,2, *}$, Yongzai $\mathrm{Xi}^{1,2}$, Hongshan Zheng ${ }^{1,2}$, Fang Ben ${ }^{1,2}$, Zhiqiang Ding ${ }^{1,2}$ and \\ Liming $\mathrm{Du}^{3}$
}

check for

updates

Citation: Lu, N.; Liao, G.; Xi, Y.; Zheng, H.; Ben, F.; Ding, Z.; Du, L. Application of Airborne Magnetic Survey in Deep Iron Ore Prospecting-A Case Study of Jinling Area in Shandong Province, China. Minerals 2021, 11, 1041. https:// doi.org/10.3390/min11101041

Academic Editor: Stanisław Mazur

Received: 21 August 2021

Accepted: 22 September 2021

Published: 26 September 2021

Publisher's Note: MDPI stays neutral with regard to jurisdictional claims in published maps and institutional affiliations.

Copyright: (c) 2021 by the authors. Licensee MDPI, Basel, Switzerland. This article is an open access article distributed under the terms and conditions of the Creative Commons Attribution (CC BY) license (https:/ / creativecommons.org/licenses/by/ $4.0 /)$.
1 Institute of Geophysical and Geochemical Exploration, Chinese Academy of Geological Sciences (CAGS), China Geological Survey (CGS), Langfang 065000, China; luning@mail.cgs.gov.cn (N.L.); xyongzai@mail.cgs.gov.cn (Y.X.); zhongshan@mail.cgs.gov.cn (H.Z.); bfang@mail.cgs.gov.cn (F.B.); dzhiqiang@mail.cgs.gov.cn (Z.D.)

2 Key Laboratory of Geophysical Electromagnetic Probing Technologies, Ministry of Natural Resources (MNR), Langfang 065000, China

3 Geological Exploration Institute of Shandong Zhengyuan, China Metallurgical Geology Bureau (CMGB), Jinan 250101, China; duliming@foxmail.com

* Correspondence: lguixiang@mail.cgs.gov.cn

\begin{abstract}
With the increasing demand for mineral resources, there is an inevitable trend to carry out deep prospecting in existing old mines to find a second or even third mining space. Deep prospecting is also an affordable and practical way to prolong the lives of mines and provide a sustainable supply of mineral resources. The magnetic survey is arguably the most effective method for iron ore prospecting. In this paper, a high resolution airborne magnetic (HRAM) survey for deep iron prospecting in the Jinling iron ore cluster (JIOC) was carried out in 2018, which renewed the field magnetic data of the JIOC obtained in the 1980s. From previous studies, almost all iron deposits in the JIOC are spatially distributed in the contact zone between the intrusive rocks and the surrounding rocks. The key prospecting areas were inferred by delineating intrusive rock boundaries via boundary enhancement and edge detection methods, and one of the areas was verified by drilling.
\end{abstract}

Keywords: airborne magnetic survey; aeromagnetic; deep mineral prospecting; exhausting deposit; iron deposit; Jinling

\section{Introduction}

Iron is the earliest, most widely used and most abundant metallic element found in the world, and, in some ways, probably the most important mineral resource in humankind's history. The magnetic method is, almost certainly, the oldest geophysical exploration technique for iron ore prospecting [1]. "Swedes successfully located a new iron ore deposit using a simple declination compass in the 1640s" [2]. "Thalen-Tiberg magnetometer, invented by Thalen and modified by Tiberg in the 1880s, was a significant step forward of the magnetic survey" [2]. As an important branch of magnetic exploration methods, the aeromagnetic survey, taking the aeromagnetic induction magnetometer developed by A.A. Logachev in 1936 as an important milestone, has made outstanding contributions to the world's iron ore exploration [1-3]. Up to now, aeromagnetic exploration is still an effective method for iron ore exploration which is widely used throughout the world [4-14]. In China, it is easy to accept that the magnetic method is also the main means of iron ore exploration and that aeromagnetic exploration plays the most important role [15-21]. According to statistics, about $80 \%$ of China's iron deposits, especially concealed iron deposits, are related to aeromagnetic exploration $[15,22,23]$.

With the growing demand for steel as reform and opening-up progresses, China is now the world's largest steel-producing and consuming country. But China's rich-iron ore 
is very dependent on imports. For example, China imported 1.069 billion tons of iron ore in 2019 [24]. Due to the huge demand for iron and steel consumption, the China government proposed in 2004 to carry out deep prospecting in Hebei, Anhui, Shanxi, Shandong, Hubei and other important iron ore producing provinces in the "the Program of Superseding Resources Prospecting in Crisis Mines in China" [25]. Many breakthroughs have been made after the implementation of two-period projects. Many iron ore deposits have been discovered in the middle and lower reaches of the Yangtze River (MLRYR), North China plate area (NCP), Gangdis, Tangula, Western Tianshan, etc. These findings indicated the direction for a new round of iron ore explorations. Deep prospecting work, targeting hidden iron ore in the thick sedimentary coverage areas of the MLRYR and NCP, has been carried out through verification of aeromagnetic anomalies and deep drillings. The Anhui Naihe, Liaoning Dataigou and other large hidden iron deposits have been found, taking the lead in opening up second prospecting spaces [16-21,26-31]. Meanwhile, the government of Shandong Province carried out the deep prospecting project of "Second Prospecting Space (SPS)". SPS improved the iron ore exploration depths, commonly between 500 and $1000 \mathrm{~m}$, in western Shandong province. For example, in Jining and Shanxian iron deposits it was found that iron ore bodies reached depths of $1800 \mathrm{~m}[32,33]$.

The Jinling iron ore cluster(JIOC) is a typical skarn-type rich iron ore deposit, with a proven reserve of more than 160 million tons [34], associated with intermediate or basal intrusive rocks in the western Shandong (also called Luxi) iron ore cluster in the North China Craton (NCC) $[22,35,36]$. The JIOC is the oldest and longest-producing mine in Shandong Province. After more than 70 years of mining, most of the mines in the JIOC have reached the late stage of mining, facing the danger of resource exhaustion. In the JIOC area, geological work for deep prospecting was rarely carried out in the past. Most of the mines were exhausted when they were mined to 500-600 $\mathrm{m}$ (some to even less than $300 \mathrm{~m}$ ). It was promising, important and urgent to carry out deep prospecting to prolong the mining life of the JIOC. Therefore, a high-resolution airborne magnetic survey, driven by the Geological Exploration Institute of Shandong Zhengyuan (GEISZ), was carried out by the Institute of Geophysical and Geochemical Exploration (IGGE) of the Chinese Academy of Geological Sciences (CAGS) of China Geological Survey (CGS) in 2018 to renew the magnetic data of the JIOC for deep iron prospecting. In this survey, a series of aeromagnetic maps, such as aeromagnetic profile maps, aeromagnetic contour maps, aeromagnetic reduced to pole and upward maps, etc. were drawn after processing. Typical aeromagnetic anomalies were analyzed and interpreted, and some of them were further processed with 3D inversion. Some deep mineralized zones were inferred and verified by drillings.

\section{Regional Geology}

The study area is located at the Luxi uplift (also called western Shandong uplift) of the northeastern North China Craton (NCC). The NCC is a main tectonic unit of the Chinese mainland with a history of 3.8 billion years. It is mainly bounded by three orogenic belts. The north and southwest boundaries are, respectively, the Inner MongoliaDaxinganling orogen and the Qinling-Dabie orogen, and the southeast boundary is the Su-Lu orogen [37-39]. (Figure 1a) 

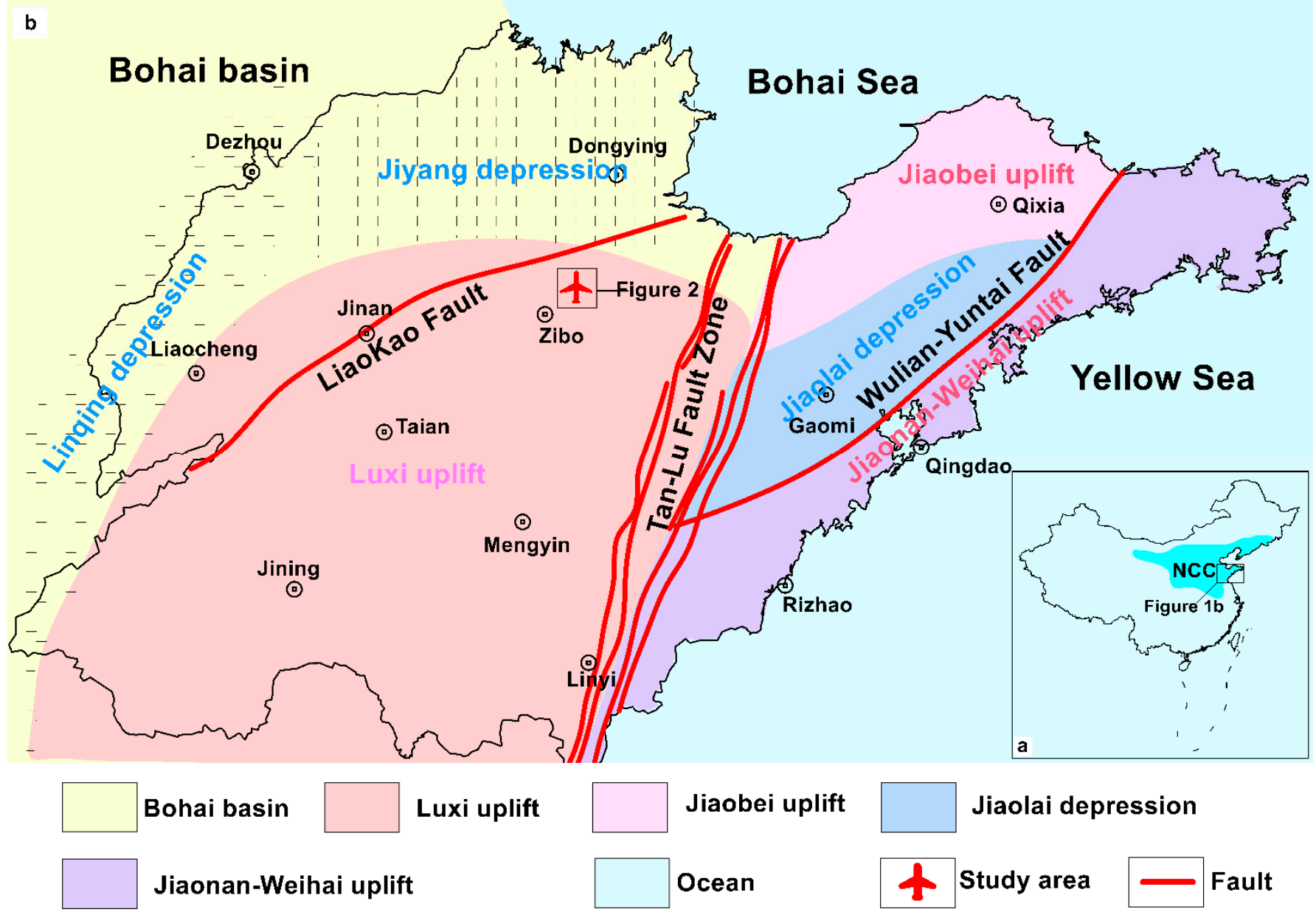

Figure 1. Tectonic map of Shandong province. (a) Location of the North China Craton (modified after [37-39]). (b) Sketch map of Shandong Province (Modified after GEISZ and [40,41]).

The Luxi uplift, located in the western part of Shandong province, is an important extensional structure in the southeastern NCC. It is spatially bounded to the north and west by the Jiyang depression and Linqing depression of the Bohai Basin, and to the east by the Tanlu Fault Zone as a contact zone connecting the Jiao Bei uplift, the Jiao Lai depression and the Jiao Nan-Weihai uplift from north to south, respectively. The frequent activities of folds, fractures and magma contributed to making the Luxi region an important concentration of skarn-type rich iron deposits in China [36,40,41] (Figure 1b).

The study area, JIOC, as mentioned above, is several kilometres away from the northeast of Zibo city. The strata of the JIOC from old to new are Ordovician (O), Carboniferous $(\mathrm{C})$, Permian $(\mathrm{P})$ and Quaternary $(\mathrm{Q})$. The Ordovician strata are mainly carbonate of the Majiagou Group, with an overall thickness of 700-800 m, of which the most closely related to mineralization is relatively pure limestone. The Carboniferous strata mainly consist of iron-alumina mudstone and fine sandstone, with a thickness of about $400 \mathrm{~m}$. The Permian strata mainly consist of sand shale and thin layer limestone, with a total thickness of about $500 \mathrm{~m}$. The flood and slope deposits of the Quaternary, mainly yellow silt clay, silt clay and silt clay, with a thickness of 60-200 m, are widely distributed (Figure 2). 


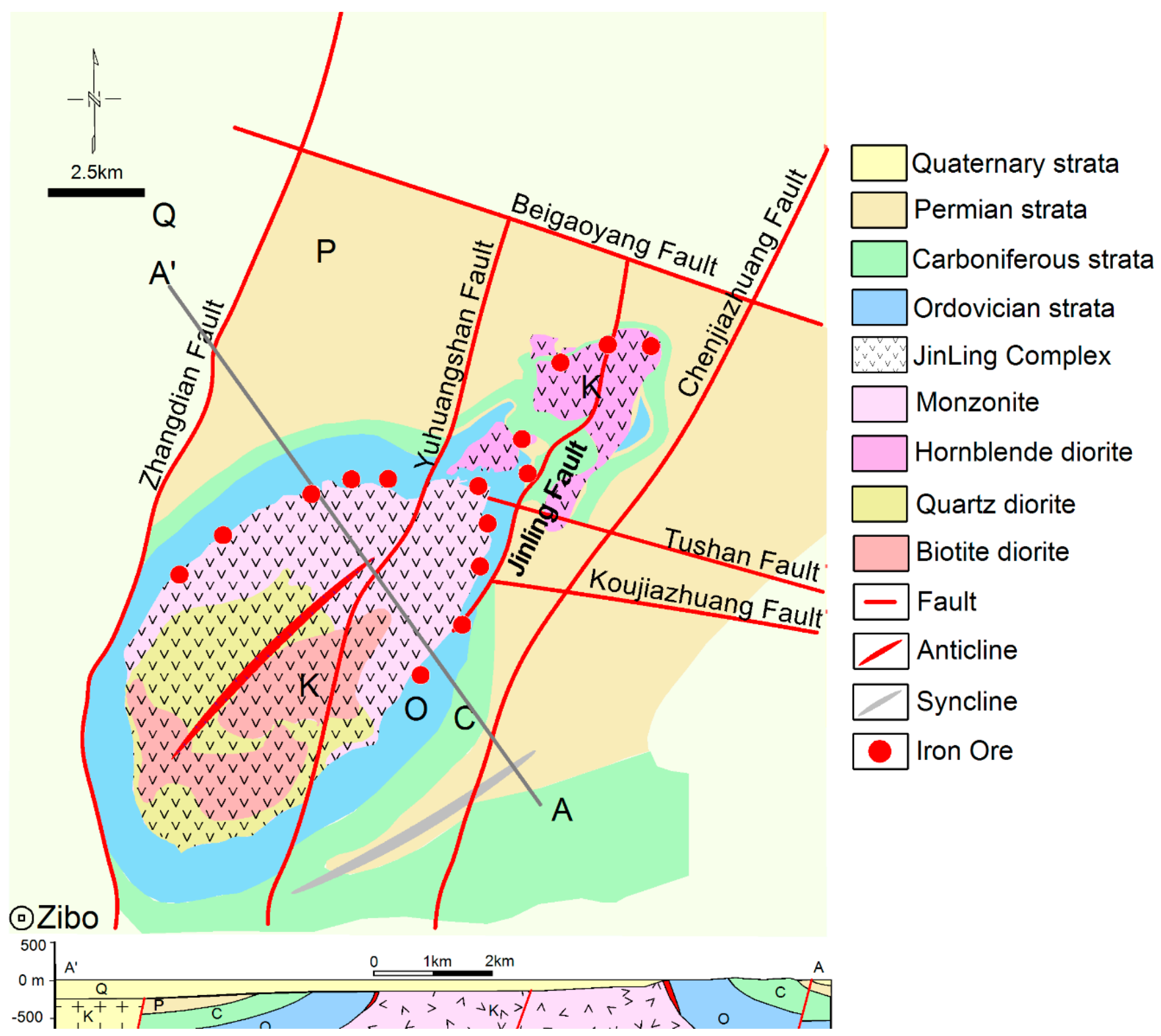

Figure 2. Geological map of the JIOC (modified after GEISZ and [35]).

The intrusive rocks of JIOC are mainly early Cretaceous fine-grained hornblende diorite (K). There are four main intrusive rock bodies, monzonite, biotite diorite, hornblende diorite and quartz diorite, that form a heterogeneous body of medium-basic-neutralmedium-basic rocks, which is known as the "Jinling Complex"(JC). The JC is distributed in a NE direction, with an intrusion time of $128 \mathrm{Ma}$ and an exposed area of about $72 \mathrm{~km}^{2}$, and is the source rock of mineralization of iron ores in the area [35,42] (Figure 2).

The fold structures of the JIOC are mainly the Jinling anticline and Hutian syncline. The Jinling anticline is N45E in strike, $20 \mathrm{~km}$ in length and $10 \mathrm{~km}$ in width. The core of the Jinling anticline is JC, and the two wings are Ordovician, Carboniferous and Permian strata. The occurrence of the Jinling anticline closer to the JC is steeper, with a dip angle of $30^{\circ}$ to $50^{\circ}$ in dip angle, compared to $20^{\circ}$ to $30^{\circ}$ to the outside. The Hutian syncline is NE-NEE in strike and located to the southeast of JC. Its northwest wing is steep with a dip angle of $20^{\circ}$ to $30^{\circ}$ and the southeast wing is gentle with a dip angle of $5^{\circ}$ to $10^{\circ}$ (Figure 2).

The faults in the Jinling area are mainly in NNE. From west to east, they are the Zhangdian fault, Yuhuangding fault, Jinling fault and Chenjiazhuang fault. The Zhangdian fault, with a strike of $20^{\circ}-30^{\circ}$, a westward dip of $75^{\circ}$ and a fault throw of more than $1 \mathrm{~km}$, 
is a normal fault located on the west side of the Jinling anticline. The Yuhuangshan fault, with a strike of NNE, a westward dip of $60^{\circ}-75^{\circ}$, a length of about $20 \mathrm{~km}$, a fault throw of $50 \mathrm{~m}$ and a displacement of $300 \mathrm{~m}-400 \mathrm{~m}$, is a compresso-shear fault located in the middle of JC. The Jinling fault, with a strike of NNE, an eastward dip of $40^{\circ}-83^{\circ}$, a length of about $10 \mathrm{~km}$, a fault throw of $120 \mathrm{~m}$ and a displacment of $200 \mathrm{~m}-300 \mathrm{~m}$, is a normal fault located on the northeast part of JC. The Chenjiazhuang fault, located roughly parallel on the east of Jinling fault, with a strike of NNE, a dip of east and a displacement of $250 \mathrm{~m}-500 \mathrm{~m}$, is a normal fault located on the northeast part of JC (Figure 2).

The statistical results of magnetic properties of the JIOC area provided by GEISZ indicate that the known iron-rich ores are mainly magnetite with very strong susceptibility and remanent magnetization, which are on average 1-2 orders of magnitude higher than diorites. The diorites have medium magnetism, and other strata are non-magnetic. The results provide the basis for this HRAM (Table 1).

Table 1. Statistical table of magnetic parameters in Jinling area (provided by GEISZ).

\begin{tabular}{|c|c|c|c|c|c|c|}
\hline \multirow{2}{*}{ Rock Type } & \multirow{2}{*}{ Location } & \multicolumn{2}{|c|}{$\kappa\left(10^{-3} \mathrm{SI}\right)^{1}$} & \multicolumn{2}{|c|}{$\operatorname{Jr}\left(10^{-3} \mathrm{~A} / \mathrm{m}\right)^{2}$} & \multirow[t]{2}{*}{ Samples } \\
\hline & & Avg. & Range & Avg. & Range & \\
\hline \multirow{10}{*}{ Magnetite } & Wangwangzhuang & 6780 & $1250-17,580$ & 130,000 & $36,000-740,000$ & 196 \\
\hline & Beijinzhaobei & 7280 & & 262,000 & & 16 \\
\hline & Nanjinzhao & 6820 & 2760-19720 & 345,000 & $270,000-1,660,000$ & 10 \\
\hline & Xinzhuang & 4530 & $1510-17,710$ & 228,000 & $160,000-1,260,000$ & 75 \\
\hline & Beijinzhao & 5640 & $2140-14,570$ & 167,000 & $50,000-1,070,000$ & 86 \\
\hline & Dongzhaoyi & 3600 & $880-15,100$ & 220,000 & $8000-860,000$ & 145 \\
\hline & Wangwangzhuangxi & 4900 & $750-15,100$ & 64,000 & $3000-650,000$ & 79 \\
\hline & Houzhuang & 5770 & $1040-49,240$ & 211,000 & $7000-384,000$ & 45 \\
\hline & Tieshan & 6410 & 3100-7780 & 83,000 & $10,000-160,000$ & 85 \\
\hline & Avg. & 5000 & $750-49,240$ & 213,000 & $7000-1,660,000$ & \\
\hline \multirow{7}{*}{ Diorite } & Wangwangzhuang & 55 & $18-85$ & 670 & $300-7140$ & 330 \\
\hline & Beijinzhaobei & 49 & $25-106$ & 600 & $40-1200$ & 180 \\
\hline & Nanjinzhao & 41 & $31-68$ & 210 & $100-340$ & 97 \\
\hline & Beijinzhao & 40 & 50-106 & 1200 & $130-4260$ & \\
\hline & Houzhuang & 36 & & 160 & & 3 \\
\hline & Liziying & 41 & $280-85$ & 1300 & $600-2560$ & \\
\hline & Avg. & 44 & $180-106$ & 700 & $100-7140$ & \\
\hline \multirow{4}{*}{ Altered diorite } & Wangwangzhuang & 25 & $10-57$ & 400 & $220-680$ & 84 \\
\hline & Nanjinzhao & 21 & & 230 & & 48 \\
\hline & Tieshan & 11 & $40-30$ & 320 & $110-900$ & 3 \\
\hline & Avg. & 19 & & 32 & & \\
\hline
\end{tabular}

${ }^{1} \mathrm{~K}$ represents susceptibility, and ${ }^{2} \mathrm{Jr}$ represents remanent magnetization. Avg. represents algebraic average.

\section{Airborne Magnetic Survey}

\subsection{Airborne Magnetic Survey System}

An Airbus AS350-B3e(H125) helicopter, carrying the aeromagnetic processing \& storage system, airborne magnetometer sensor, radar altimeter, pilot navigation unit (PGU) and fluxgate magnetometer, was used as the aeromagnetic platform in the survey. The aeromagnetic input \& processing system, radar altimeter and PGU were installed in the cabin. The magnetometer sensor and fluxgate magnetometer were installed in the stinger which was mounted under the cabin. Meanwhile, the diurnal magnetic monitoring (DMM, also called BaseMag) station was settled in a wide-open place nearby (Figure 3). 


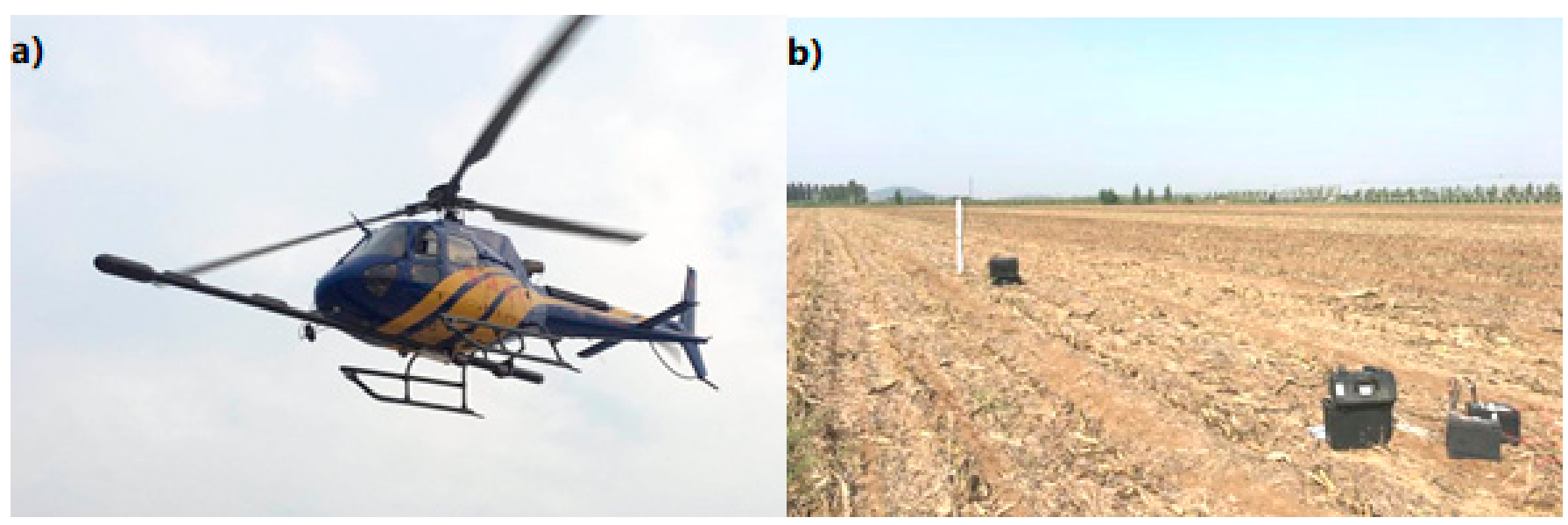

Figure 3. An overview of the aeromagnetic survey system. (a) The AS-350 B3 helicopter with a stinger taking off. (b) The BaseMag was placed nearby in the fields.

The integrated multi-parameter airborne console (IMPAC), integrated with data acquisition, navigation and aeromagnetic compensator, produced by PICO Envirotec, was used as an aeromagnetic processing and storage system. A CS-3 high sensitivity magnetometer sensor manufactured by Scintrex Ltd. (Concord, ON, Canada). was chosen to record magnetic field readings. A CG-T3 digital radar altimeter was selected to provide the height of flight. A Hemisphere Crescent R120 was used as the GPS instrument. A BILLINGSLEY AEROSPACE \& DEFENSE TFM100G2 Triaxial fluxgate magnetometer was fixed in the middle of the stinger to obtain the flight manoeuvre information of the helicopter. A PICO PGIS-HSMAG station was placed on farmland at a certain position to monitor the diurnal magnetic change. The Geosoft Oasis Montaj (Version 8.0, manufactured by Seequent Limited, Toronto, ON, Canada) was used in processing and mapping the magnetic data.

\subsection{Survey Flight}

\subsubsection{Survey Lines}

The terrain of the survey area is low in the north and high in the south. The highest place is Tushan Hill in the south-central part of the survey area, with an altitude of 169 $\mathrm{m}$ (Figure 4a). The other elevation differences are generally less than $50 \mathrm{~m}$. According to the distribution of geological structures, the direction of survey lines (SL) was designed as NW-SE $\left(135^{\circ}-315^{\circ}\right)$, and the distance between SLs was $100 \mathrm{~m}$. The direction of tie lines (TL) was perpendicular to the main survey lines with a spacing of $1.5 \mathrm{~km}$ (Figure $4 \mathrm{~b}$ ). In September 2020, the 194 SLs and 6 TLs, with a total length of $1200 \mathrm{~km}$, had been flown in 2 days.

\subsubsection{Test Flight}

(1) Compensation and Heading Error Test

To improve the quality of the aeromagnetic data, it is necessary to carry out an aeromagnetic compensation flight before the survey flight and after maintenance. The compensation flight is essential and effective for high-quality aeromagnetic survey, as it reduces magnetic interference and noise caused by the maneuvers of the aircraft flying within the Earth's magnetic field, and the heading error test flight ("Clover-leaf" test flight) is an easy way to determine and reduce the error when the aircraft changes heading during flight [43-47]. In this survey, the compensation and clover-leaf test flight were carried out at an altitude of $3000 \mathrm{~m}$ to reduce the artificial magnetic influence on the ground (Figure 5).

\section{(2) LAG Test}

A LAG test flight is used to determine the magnetic field variations in opposite flight directions and to reduce the offset effect caused by the installation distance between the magnetometer sensor and GPS antenna (Figure 6). 


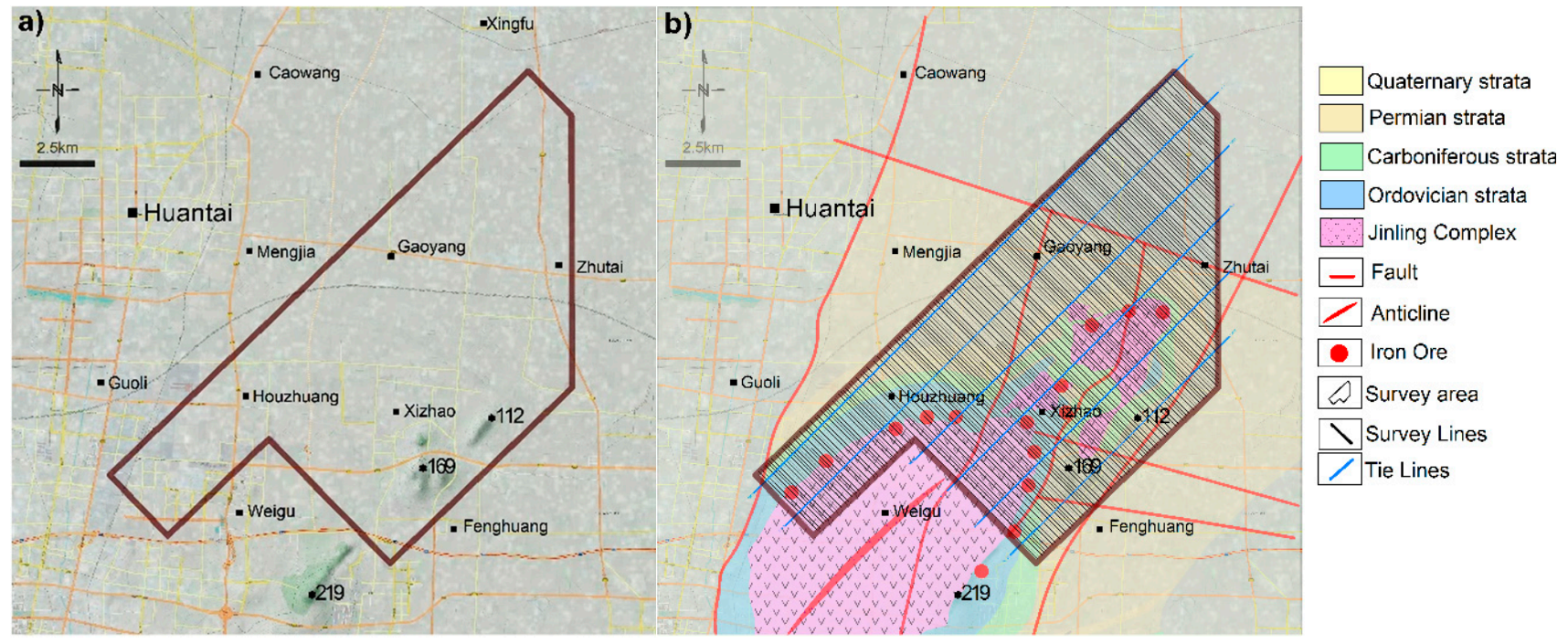

Figure 4. Map of the survey area and the designed survey plan. (a) The topography of the survey area is mainly plain, except for two 100m-high hills between Xizhao and Fenghuang. (b) Flight plan of the survey area.

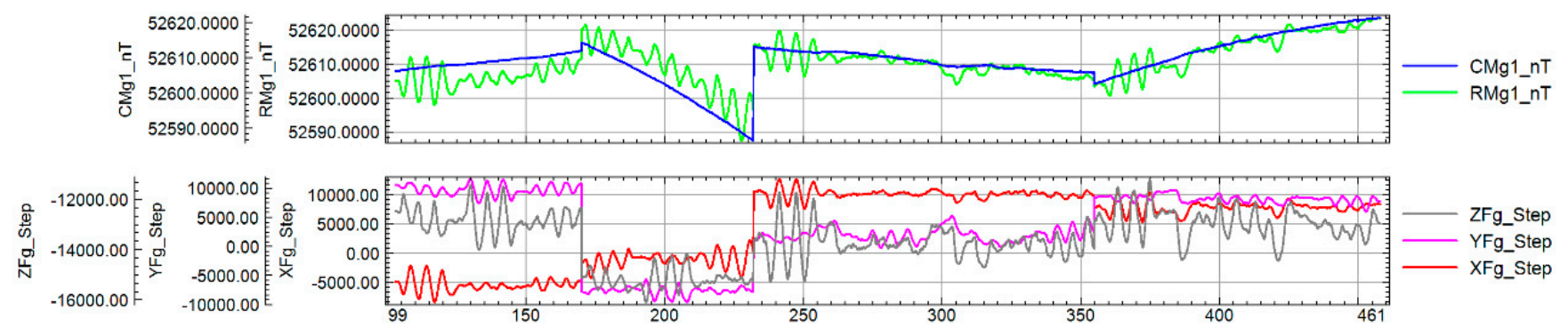

Figure 5. The compensation flight profiles. $\mathrm{CMg}$ and $\mathrm{RMg}$ represent compensated and uncompensated magnetic fields. $\mathrm{XFg}$, YFg and ZFg represent three components of data acquired from the fluxgate magnetometer.

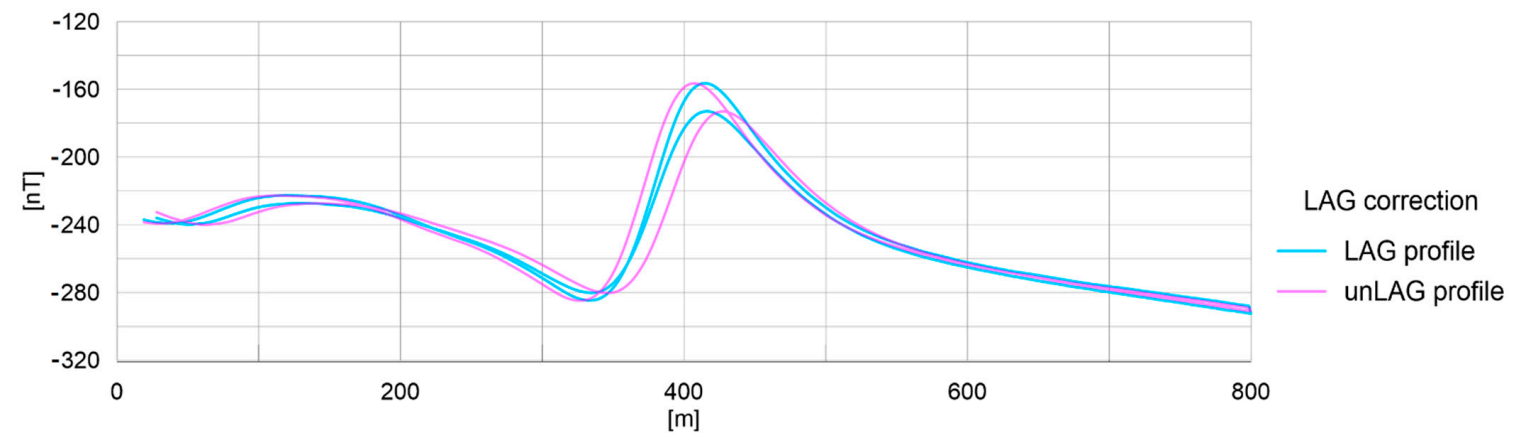

Figure 6. LAG test flight profiles were plotted on the same $X$ and $Y$ axes. The anomaly centres are aligned after a $0.5 \mathrm{~s}$ LAG correction was applied.

\subsubsection{Corrections}

(1) Diurnal Magnetic Correction

Diurnal magnetic Correction (DMC) or BaseMag Correction (BMC) is used to eliminate the influence of periodic daily variation and short-term disturbance of the geomagnetic field $[48,49]$. The BaseMag Station (BMS) is generally placed nearby the survey area where the magnetic field is stable (Figure 7). In this survey, the BMS was located on a farm between the survey area and the landing point. The DMM and aeromagnetic were both set sampling rates at $10 \mathrm{~Hz}$. The DMC was computed point by point according to GPS time. 


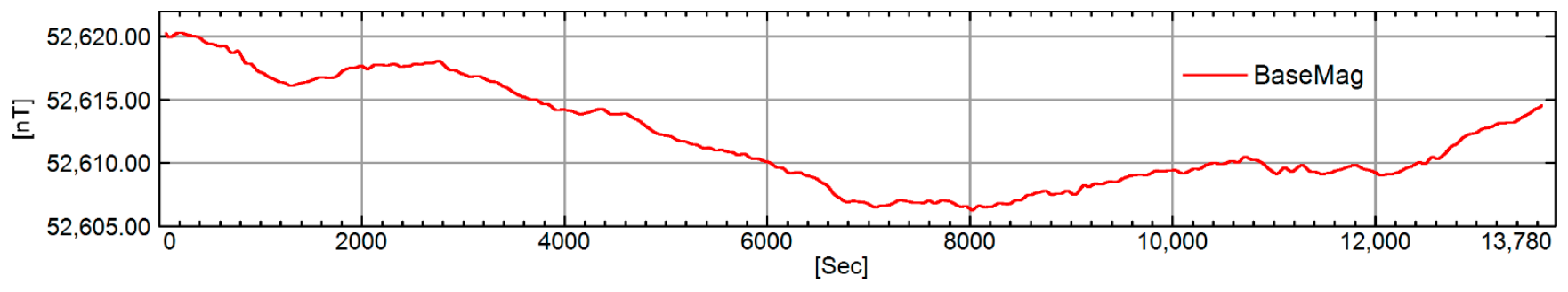

Figure 7. A diurnal magnetic field curve acquired from the BMS.

(2) Lag Correction

According to the flight results of the LAG test (Figure 6), the magnetic field of different directions is corrected to make the magnetic field value of each measuring point as close to the actual space position as possible.

\section{(3) Background Removal}

In aeromagnetic measurement, the measured magnetic field value can simply be understood as the vector sum of the normal geomagnetic background field and the magnetic anomaly field, and removing the normal geomagnetic background field can obtain magnetic anomaly information [46]. The International Geomagnetic Reference Field (IGRF) was established in 1965 by the International Association of Geomagnetism and Aeronomy (IAGA) and updated every 5 years [50,51]. IGRF correction is now the most common and widely used method of normal geomagnetic background field removal.

After the above processing and correction of the measured aeromagnetic data, the commonly-known anomaly magnetic map was obtained (Figure 8a).

\subsection{Data Processing}

\subsubsection{Reduction to the Magnetic Pole}

To eliminate the influence of geomagnetic inclination and declination on magnetic anomaly data, reduction to the magnetic pole (RTP) should be applied to convert inclination to the vertical and declination to the north. RTP can effectively eliminate the repeated superposition of positive and negative anomalies in the original data, thus reducing the complexity of the anomalies and making them better correlate with the geological units. Most of the anomalies are narrowed down after RTP processing, and the morphology becomes simpler and easier for interpretation. RTP processing was according to the geomagnetic inclination of $55.35^{\circ}$ and geomagnetic declination of $-6.69^{\circ}$ in this region.

The colour-shaded grid maps of magnetic anomaly (Figure 8a) and RTP (Figure 8b) show the excellent correspondence between the aeromagnetic data and the geological units. As clearly seen, Figure 8 shows that the strong positive magnetic field generated by the JC and iron ores present an expected result of this survey, according to the magnetic parameters (Table 1).

\subsubsection{Low Pass Filter}

Due to the superposition of different wavelength fields of geological bodies of different depths and scales, some anomalies become very complicated and are difficult to identify, which creates difficulties for geological interpretation. In the Jinling area, artificial objects such as factories generate many high-frequency magnetic signals, which would, more or less, generate interference in the boundary enhancement and other work. Therefore, a $3 \times 3$ convolution filter was applied to the RTP to properly suppress the high-frequency magnetic signals. 


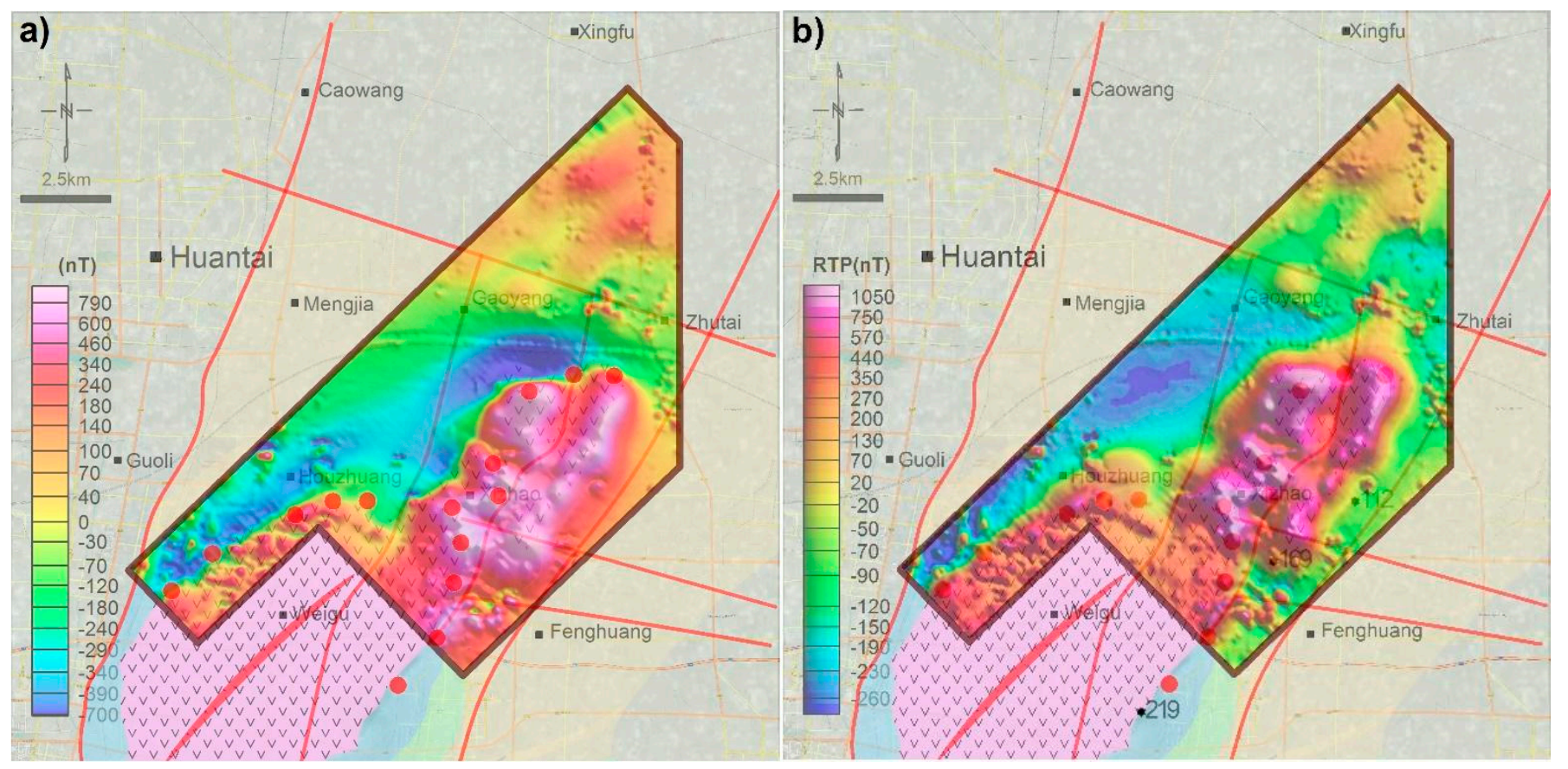

Figure 8. Colour-shaded grid map of HRAM data. (a) Magnetic anomaly map. (b) RTP magnetic map. The gridding method is Minimum Curvature with a cell size of $50 \mathrm{~m}$. TMI and RTP are set to $40 \%$ transparency and superimposed on the geological map.

\subsubsection{Boundary Enhancement and Edge Detection}

Boundary enhancement often refers to the conversion of measured magnetic anomaly data using numerical conversion techniques, to highlight numerical features near the source boundary in the converted data for further use in the identification of the source boundary (edge detection).

Derivative analysis is the major research direction of boundary feature enhancement, which focuses on the various characteristics of the derivatives of anomalous data and has a long history and variety of methods. Methods such as the vertical derivative (VDR) [52] and the second-order vertical derivative (SVDR) [53-55] of the total field or components data can tighten the anomaly, and the zero value of VDRs refers to the edges of the body. The VDR and SVDR are formulated as follows:

$$
\begin{gathered}
V D R=\frac{\partial T}{\partial z}, \\
S V D R=\frac{\partial^{2} T}{\partial z^{2}},
\end{gathered}
$$

where $T$ is the magnetic anomaly field and $z$ is the vertical derivative direction. Note that as the depth of the field source increases, the magnetic anomaly becomes wider and slower, leading to an outward expansion of the zero value points of VDR and SVDR, thus deviating from the true geological boundaries.

Conversely, the maximum value of the total horizontal gradient (THD) is located at the anomaly boundary [56,57]. In addition, the analytic signal (AS) method is also a basic method of boundary enhancement, and its maximum values can be used as markers to identify the boundary of a field source $[58,59]$. The equations of THD and AS are as follows:

$$
T H D=\sqrt{\left(\frac{\partial T}{\partial x}\right)^{2}+\left(\frac{\partial T}{\partial y}\right)^{2}}
$$




$$
A S=\sqrt{\left(\frac{\partial T}{\partial x}\right)^{2}+\left(\frac{\partial T}{\partial y}\right)^{2}+\left(\frac{\partial T}{\partial z}\right)^{2}},
$$

where $T$ is the magnetic anomaly field, $\frac{\partial T}{\partial x}, \frac{\partial T}{\partial y}$ and $\frac{\partial T}{\partial z}$ are the derivatives in $x, y$ and $z$ directions, respectively. THD and AS both have the disadvantages of being insensitive to weak anomalies adjacent to strong anomalies and deeply buried geological bodies.

Since the magnetic anomalies from deep field sources are often covered by shallow ones, the tilt angle method (Tilt) [60] has been proposed to identify the boundaries of sources at different depths:

$$
\text { Tilt }=\tan ^{-1}\left(\frac{\frac{\partial T}{\partial z}}{\sqrt{\left(\frac{\partial T}{\partial x}\right)^{2}+\left(\frac{\partial T}{\partial y}\right)^{2}}}\right),
$$

which is less affected by the burial depth of the field source and can simultaneously enhance the boundaries of sources with different anomaly amplitudes, but the position of the localized boundaries is seriously affected by the magnetization direction.

Based on the above methods, many improved methods have been developed, such as the following:

The total horizontal derivative of the tilt angle (THD_Tilt) [61]:

$$
\text { THD_Tilt }=\sqrt{\left(\frac{\partial T i l t}{\partial x}\right)^{2}+\left(\frac{\partial T i l t}{\partial y}\right)^{2}},
$$

where Tilt is calculated in Equation (5). The maximum value of THD_Tilt is located at the edge of the body. THD_Tilt can approximately recognize the edges of deep anomalies but is not capable of separating anomalies very close together.

The Theta method $(\theta)$ [62]:

$$
\text { Theta }=\cos ^{-1}\left(\frac{V D R}{A S}\right),
$$

where $V D R$ and $A S$ are calculated in Equations (1) and (4), respectively. The value of Theta is between 0 and 1 , and it uses the maximum value to locate the boundary position. The method is less affected by the burial depth of the field source and can enhance both deep and shallow anomaly boundaries, but it has the disadvantages of sensitivity to noise, and estimated edges that are more dispersed and wider than they actually are.

The analytic signal of Tilt angle (AS_Tilt) [63]:

$$
\text { AS_Tilt }=\sqrt{\left(\frac{\partial T i l t}{\partial x}\right)^{2}+\left(\frac{\partial T i l t}{\partial y}\right)^{2}+\left(\frac{\partial T i l t}{\partial z}\right)^{2}},
$$

which uses its maximum value position to locate the boundary. However, the method is extremely sensitive to noise and does not enhance the boundary well enough.

The Tilt angle of analytic signal (Tilt_AS) [64]:

$$
\text { Tilt_AS }=\tan ^{-1}\left(\frac{\frac{\partial A S}{\partial z}}{\sqrt{\left(\frac{\partial A S}{\partial x}\right)^{2}+\left(\frac{\partial A S}{\partial y}\right)^{2}}}\right),
$$

The vertical derivative of analytic signal (VDR_AS) [65]:

$$
V D R \_A S=\frac{\partial A S}{\partial z}
$$


where both use their maximum value to delineate the boundary. Since they use AS as the input source, the two methods also suffer from insufficient enhancement of deep field sources.

Researchers are continuously comparing the advantages and disadvantages of boundary enhancement and edge detection methods and proposing newer methods [66-69]. From these studies above, we selected several commonly used methods and the STDR filter presented by [68] to detect the boundaries of HRAM in the JC area (Figure 9).

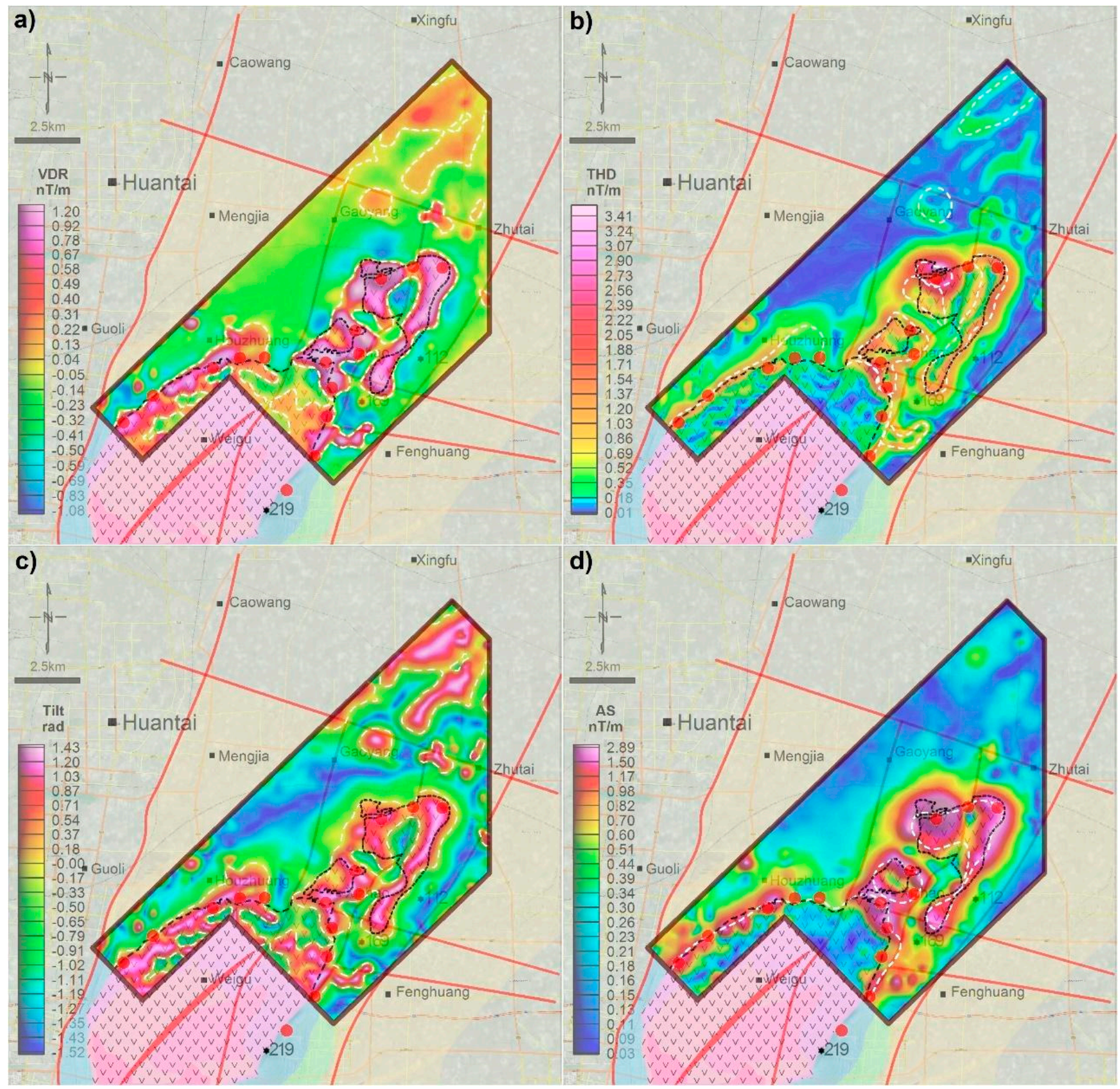

Figure 9. Cont. 


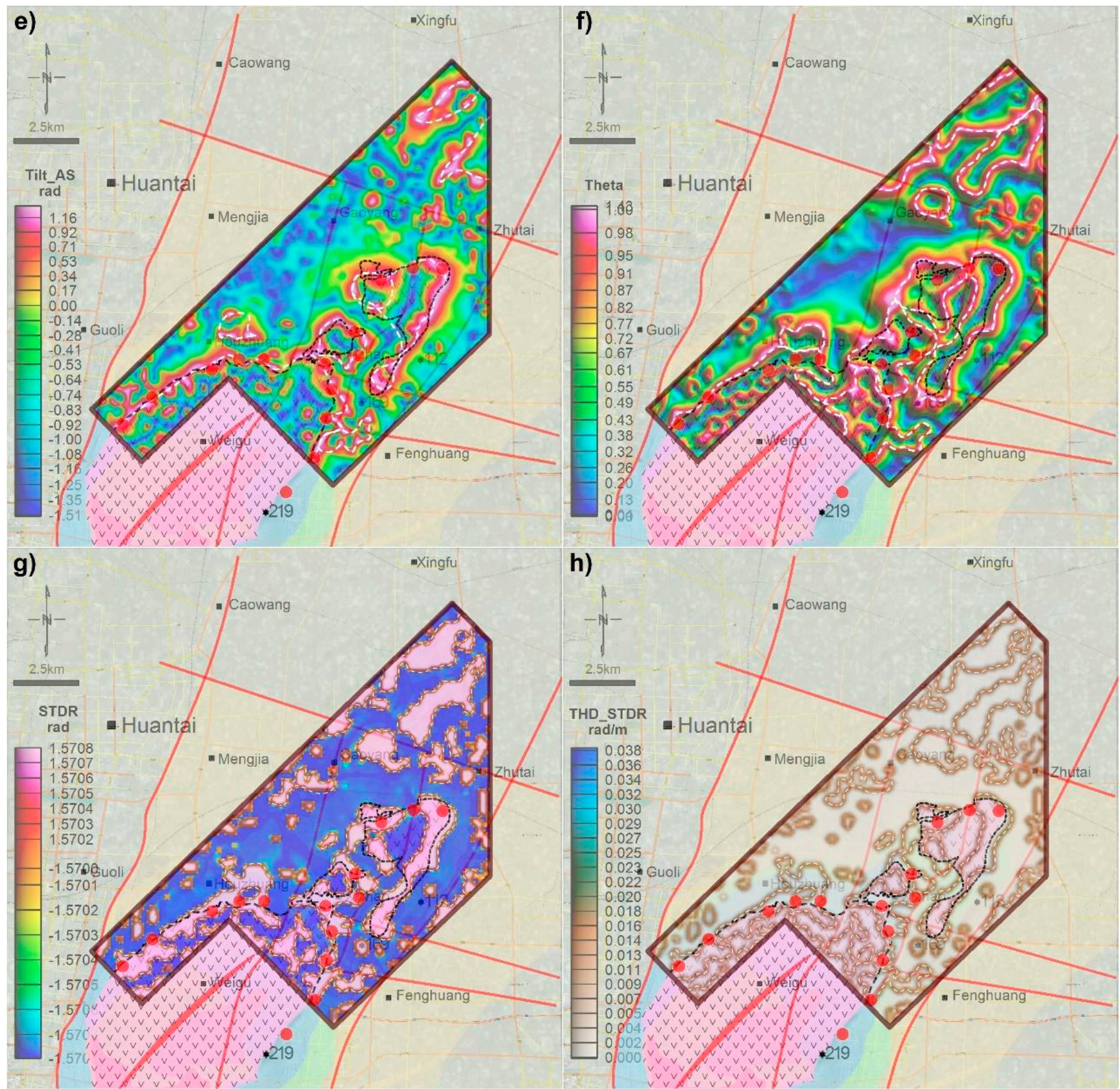

Figure 9. Application of selected boundary enhancement filters to HRAM data measured from the JC area. (a) VDR. (b) THD. (c) Tilt angle map. (d) AS. (e) Tilt of AS. (f) Theta map. (g) STDR. (h) THD of STDR. Black dash lines are the outlines of JC from the geological map. White dash lines are the inferred edge of the JC. All filter maps are set to $40 \%$ transparency and superimposed on the geological map to give a relatively easy way to observe the correlation between them. Red dots represent iron deposits.

The STDR filter was introduced as follows:

$$
S T D R=\tan ^{-1}\left(M \frac{S V D R}{\sqrt{\left(\frac{\partial T H D}{\partial x}\right)^{2}+\left(\frac{\partial T H D}{\partial y}\right)^{2}}}\right)
$$


where SVDR and THD are calculated in Equations (2) and (3), respectively. $M$ is a constant given by the average total magnetic field intensity of the region. The maximum and minimum values of STDR delineate the range of positive and negative anomalies, respectively. STDR normalises the intensity of deep and shallow anomalies as well as different anomalies distributed very close to each other. A really excellent application of STDR for identifying the submarine geological boundaries in the northern Scandinavia coastal zone is shown in paper [68], where the detected boundaries are highly accurate and well recognized. The total horizontal derivative of STDR (THD_STDR) was also introduced in the paper [68] to get a better presentation of the detected boundaries.

\section{Results and Discussion}

Figure 9 shows the results from applying the boundary enhancement and edge detection methods including VDR, THD, Tilt, AS, Tilt_AS, Theta map, STDR and THD_STDR to the measured HRAM data from the JC area. Compared with TMI and RTP (Figure 8), these figures show that the range of aeromagnetic anomalies over the JC have been significantly narrowed and subdivided into smaller ones, and all applied methods have produced their effects. According to the different algorithms, VDR (Figure 9a), Tilt (Figure 9c) and STDR (Figure 9g) use their zero lines (white dashed line in the figures) as the boundaries of the magnetic anomaly. Meanwhile, THD (Figure 9b), AS (Figure 9d), Tilt_AS (Figure 9e), Theta map(Figure 9f) and THD_STDR (Figure 9h) are represented by their maximum values (white dashed lines in the figures).

From Figure 9, it iss easy to see that VDR, THD, AS and Tilt_AS have poor effects on the two weak banded anomalies in the northern part of the study area and AS completely suppressed them. All methods reflect that the north part of the JC (NJC) is composed of multiple small rock masses. But VDR, THD, AS and Tilt_AS do not reflect the small rock body boundaries clearly. This is because the northern part of the study area is deeply covered and the anomalies generated by deep field sources are weak, and the NJC is composed of magnetically variable rock and ore bodies, producing complex magnetic anomalies of varying intensity and proximity. As described above, these four methods have insufficient resolution for the deep weak anomalies and adjacent anomalies. Comparatively, Tilt, Theta, STDR and THD_STDR have better descriptions of the boundaries. Consequently, by comparison, the performance of STDR is the most balanced, which not only enhances weak anomalies but also shows most internal details of the JC. Further, THD_STDR shows the edges with a higher resolution. Therefore, STDR is used to infer the JC boundaries, and mineralization areas are proposed accordingly (Figure 10a).

According to previous studies, the JC was formed by magma intruding from the north-east to south-west along with the fracture structures, with the intrusion becoming progressively shallower in depth [34]. Figure 10a shows the inferred distribution (blue dots area) of the rocks based on the newly measured HRAM data. The contact zones between the JC and the surrounding strata control the morphology of the iron ore bodies and indicate favourable locations for mineralisation. Therefore, we recommend several deep prospective areas in the outer edge of the inferred NJC internal minor rock bodies (zones 1-3 in Figure 10a) and the inferred deep intrusive rock zone in the northern part of the study area (zones 4-5 in Figure 10a). Deep exploration is suggested for implementation in zones $1-3$ as a priority, as they are located within the JIOC. Zones $4-5$ are the inferred concealed rocks areas that have not been previously investigated, therefore it is recommended that prospecting should first be carried out in Zone 4 and then enlarged to Zone 5 after some progress has been made. 

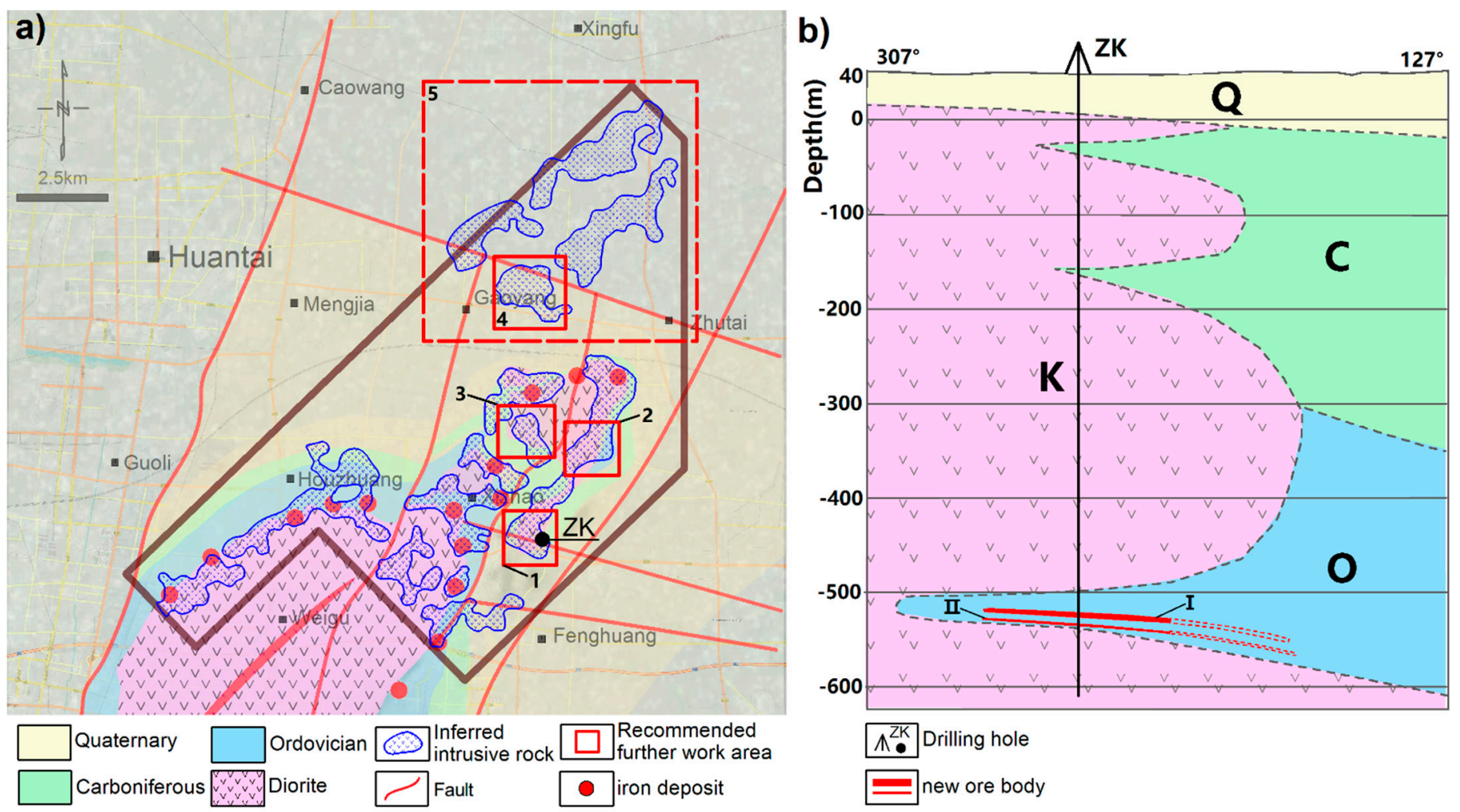

Figure 10. (a) Inferred intrusive rock boundaries and recommended further work areas. (b) Simple geological profile of drilling hole (modified after GEISZ).

Engineers from GEISZ carried out a drill verification firstly in area 1 in 2020 and have successfully discovered two new iron ore layers below a depth of $550 \mathrm{~m}$ (Figure 10b). The upper layer is $6.3 \mathrm{~m}$ thick and the lower one is $2.9 \mathrm{~m}$ thick. Both ore bodies are located in the skarn belt which developed along the intrusive rocks and carbonate contact zones. Based on the intrusive rock boundaries inferred from HRAM, the location of the ZK drill hole is on the eastern edge of the intrusive rock body and the main part of the newly discovered ore body should be located on the eastern side of the drill hole.

\section{Conclusions}

Based on the statistical mineralisation rule that all of the iron ore deposits of the JIOC are distributed in the contact zones between intrusive and carbonate rocks, the HRAM data was used to recognize the intrusive rock edges using boundary enhancement techniques, and new ore bodies were found at the outer border of the inferred rock masses. This has demonstrated the effectiveness of aeromagnetic surveys in the search for deep magnetic deposits. Due to various reasons, this deep iron ore prospecting has not been carried out with fine interpretation such as inversion, nor has it been possible to verify the inferred deep rock bodies in the northern part of the study area. It is recommended that subsequent researchers in this area could make better use of the newly measured HRAM data for fine processing interpretation such as 3D inversion to make greater breakthroughs.

Author Contributions: Conceptualization, N.L., Z.D. and L.D.; methodology, G.L. and Y.X.; validation, H.Z. and Z.D.; investigation, N.L. and H.Z.; resources, L.D.; data curation, N.L. and F.B.; writing-original draft preparation, N.L. and G.L.; writing-review and editing, N.L. and G.L.; visualization, N.L.; project administration, Z.D. All authors have read and agreed to the published version of the manuscript.

Funding: This research was funded by National Key Research and Development Program of China (No. 2016YFC0600209 and No. 2017YFC0602000) and Public Welfare Geological Survey Project of Anhui Province (No. 2018-g-1-6). 
Acknowledgments: The Digital Elevation Model (DEM) data was collected from Geospatial Data Cloud. The authors would like to thank the anonymous reviewers and editors for their valuable suggestions.

Conflicts of Interest: The authors declare no conflict of interest.

\section{References}

1. Nabighian, M.N.; Grauch, V.J.S.; Hansen, R.O.; LaFehr, T.R.; Li, Y.; Peirce, J.W.; Phillips, J.D.; Ruder, M.E. The Historical Development of the Magnetic Method in Exploration. Geophysics 2005, 70, 33ND-61ND. [CrossRef]

2. Viberg, A.; Trinks, I.; Lidén, K. A Review of the Use of Geophysical Archaeological Prospection in Sweden. Archaeol. Prospect. 2011, 18, 43-56. [CrossRef]

3. Logachev, A.A.; Hawkes, H.E. The Development and Applications of Airborne Magnetometers in the U.S.S.R. Geophysics 1946, 11, 135-147. [CrossRef]

4. Bubner, G.; Hills, R.; Dhu, T.; Dentith, M. Geophysical Exploration for Iron Ore in the Middleback Ranges, South Australia. ASEG Ext. Abstr. 2003, 2003, 29-46. [CrossRef]

5. Abulghasem, Y.A.; Akhir, J.M.; Samsudin, A.R.; Hassan, W.F.W.; Youshah, B.M. Integrated Data of Remote Sensing and Geophysical Data for Iron Ore Exploration in the Western Part of Wadi Shatti District, Libya. EJGE 2011, 16, $1441-1454$.

6. CunnInGhaM, M.I.C.; De Waele, B. Geological Mapping of Badondo and Iron Mineralisation Targets, Republic of Congo. Struct. Geol. Resour. 2012, 2012, 54-56.

7. Mieth, M.; Jokat, W. Banded Iron Formation at Grunehogna Craton, East Antarctica-Constraints from Aeromagnetic Data. Precambrian Res. 2014, 250, 143-150. [CrossRef]

8. Leao-Santos, M.; Li, Y.; Moraes, R. Application of 3D Magnetic Amplitude Inversion to Iron Oxide-Copper-Gold Deposits at Low Magnetic Latitudes: A Case Study from Carajas Mineral Province, Brazil. Geophysics 2015, 80, B13-B22. [CrossRef]

9. Oladunjoye, M.A.; Olayinka, A.I.; Alaba, M.; Adabanija, M.A. Interpretation of High Resolution Aeromagnetic Data for Lineaments Study and Occurrence of Banded Iron Formation in Ogbomoso Area, Southwestern Nigeria. J. Afr. Earth Sci. 2016, 114, 43-53. [CrossRef]

10. Mazhari, N.; Shafaroudi, A.M.; Ghaderi, M. Detecting and Mapping Different Types of Iron Mineralization in Sangan Mining Region, NE Iran, Using Satellite Image and Airborne Geophysical Data. Geosci. J. 2017, 21, 137-148. [CrossRef]

11. Ives, B.T.; Mickus, K. Using Gravity and Magnetic Data for Insights into the Mesoproterozoic St. Francois Terrane, Southeast Missouri: Implications for Iron Oxide Deposits. Pure Appl. Geophys. 2019, 176, 297-314. [CrossRef]

12. Raju, P.V.S.; Kumar, K.S. Magnetic Survey for Iron-Oxide-Copper-Gold (IOCG) and Alkali Calcic Alteration Signatures in Gadarwara, M.P, India: Implications on Copper Metallogeny. Minerals 2020, 10, 671. [CrossRef]

13. Voll, E.; Silva, A.M.; Pedrosa-Soares, A.C. Tracking Iron-Rich Rocks beneath Cenozoic Tablelands: An Integration of Geological, Airborne Geophysical and Remote Sensing Data from Northern Minas Gerais State, SE Brazil. J. S. Am. Earth Sci. 2020, 101, 102604. [CrossRef]

14. Harikumar, P.; Rajaram, M.; Balakrishnan, T.S. Aeromagnetic Study of Peninsular India. Proc. Indian Acad. Sci. Earth Planet. Sci. 2000, 109, 381-391. [CrossRef]

15. Yao, P. Records of China's Iron Ore Deposits; Metallurgic Industry Press: Beijing, China, 1993; ISBN 978-7-5024-1449-8.

16. Changchun, Y.; Zhengguo, F.; Naidong, Y.; Shengqing, X.; Jianhua, W.; Hongrui, Z. High-resolution aeromagnetic exploration methods and their application in daye iron mines. Prog. Geophys. 2007, 22, 979-983.

17. Minan, W.; Qingsong, W.; Guangwen, Z.; Xiaobin, C.; Shixue, Y.; Qinson, D. Discovery of the Nihe Iron Deposit in Lujiang, Anhui, and its Exploration Significance. Acta Geol. Sin. 2011, 85, 802-809.

18. Teng, S.; Wen, D.; Hong, X.; Zhang, H. Perspective resources estimated by comprehensive information technology for the Dataigou iron deposit in Liaoning province. Geol. Resour. 2013, 22, 199-203.

19. Wang, F.; Li, W. Application of MT method to anomly recognition during deep iron ore prospecting in Qian'an iron ore. Contrib. Geol. Miner. Resour. Res. 2013, 28, 604-612.

20. Fan, Z.; Huang, X.; Yang, X.; Zhou, D.; Liu, Q. Aeromagnetic Exploration of Deep Iron Ore in Daye, China. Acta Geol. Sin. Engl. Ed. 2014, 88, 1233-1234. [CrossRef]

21. Zhang, J.; Zeng, Z.; Zhao, X.; Li, J.; Zhou, Y.; Gong, M. Deep Mineral Exploration of the Jinchuan Cu-Ni Sulfide Deposit Based on Aeromagnetic, Gravity, and CSAMT Methods. Minerals 2020, 10, 168. [CrossRef]

22. Zhao, Y. Main genetic types and geological characteristics of iron-rich ore deposits in China. Miner. Depos. 2013, 32, 686-705. [CrossRef]

23. Zhao, Y.; Feng, C.; Li, D. The Major Ore Clusters of Super-Large Iron Deposits in the World, Present Situation of Iron Resources in China, and Prospect. Acta Geol. Sin. Engl. Ed. 2014, 88, 1895-1915. [CrossRef]

24. General Administration of Customs of the People's Republic of China Review of China's Foreign Trade in 2019. Available online: http:/ / english.customs.gov.cn/Statics / f63ad14e-b1ac-453f-941b-429be1724e80.html (accessed on 20 September 2020).

25. Wu, J. Deep-felt consideration and important decision-The issue of "the Program Of Superseding Resources Prospecting in Crisis Mines in China (2004-2010)". Resour. Ind. 2005, 7, 25-26.

26. Liu, Y.; Yan, J.; Wu, M.; Zhao, W.; Zhao, J.; Deng, Z. Exploring Deep Concealed Ore Bodies Based on Gravity Anomaly Separation Methods: A Case Study of the Nihe Iron Deposit. Diqiu Wuli Xuebao 2012, 55, 4181-4193. [CrossRef] 
27. Liu, S.; Hu, X.; Cai, J.; Li, J.; Shan, C.; Wei, W.; Han, Q.; Liu, Y. Inversion of Borehole Magnetic Data for Prospecting Deep-Buried Minerals in Areas with near-Surface Magnetic Distortions: A Case Study from the Daye Iron-Ore Deposit in Hubei, Central China. Near Surf. Geophys. 2017, 15, 298-310. [CrossRef]

28. Liu, S.; Hu, X.; Zhu, R. Joint Inversion of Surface and Borehole Magnetic Data to Prospect Concealed Orebodies: A Case Study from the Mengku Iron Deposit, Northwestern China. J. Appl. Geophys. 2018, 154, 150-158. [CrossRef]

29. Shi, R.; Zhang, Y.; Lu, M.; Kuang, H.; Zhang, G. 3D Metallogenic Prediction Based on Geological and Gravity-magnetic Data Integration in the Qian'an Iron Ore Concentration Area, Hebei Province. Acta Geosci. Sin. 2018, 39, 762-770.

30. Liu, S.; Fedi, M.; Hu, X.; Ou, Y.; Baniamerian, J.; Zuo, B.; Liu, Y.; Zhu, R. Three-Dimensional Inversion of Magnetic Data in the Simultaneous Presence of Significant Remanent Magnetization and Self-Demagnetization: Example from Daye Iron-Ore Deposit, Hubei Province, China. Geophys. J. Int. 2018, 215, 614-634. [CrossRef]

31. Sun, S.; Chen, C.; Liu, Y. Constrained 3D Inversion of Magnetic Data with Structural Orientation and Borehole Lithology: A Case Study in the Macheng Iron Deposit, Hebei, China. Geophysics 2019, 84, B121-B133. [CrossRef]

32. Mingchun, S.; Peiyuan, L.I.; Yuxin, X.; Guopu, W.; Zhaotong, M. Deep Iron Deposit of the Jining Intense Magnetic Anomaly Area in Shandong Province and Its Significance. Acta Geol. Sin. 2008, 82, 1285-1291.

33. Zhao, F.; Cao, X.; Pang, X.; Zang, K.; Sun, L. Application and Ore-forming Predication of High-precision Magnetic Survey in Longwangmiao Iron Deposit in Shanxian County. Shandong Land Resour. 2011, 27, 23-26, 30.

34. Ma, J.; Xu, X.; Yuan, P. Discussion on Mineralization Rule of Jinling Diggings. Shandong Metall. 2004, 26, 6-8. [CrossRef]

35. Jin, Z.; Zhang, Z.; Hou, T.; Santosh, M.; Han, L. Genetic Relationship of High-Mg Dioritic Pluton to Iron Mineralization: A Case Study from the Jinling Skarn-Type Iron Deposit in the North China Craton. J. Asian Earth Sci. 2015, 113. [CrossRef]

36. Zhang, Z.; Hou, T.; Santosh, M.; Li, H.; Li, J.; Zhang, Z.; Song, X.; Wang, M. Spatio-Temporal Distribution and Tectonic Settings of the Major Iron Deposits in China: An Overview. Ore Geol. Rev. 2014, 57, 247-263. [CrossRef]

37. Zhao, G.; Wilde, S.A.; Cawood, P.A.; Sun, M. Archean Blocks and Their Boundaries in the North China Craton: Lithological, Geochemical, Structural and P-T Path Constraints and Tectonic Evolution. Precambrian Res. 2001, 107, 45-73. [CrossRef]

38. Zhai, M.-G.; Santosh, M. The Early Precambrian Odyssey of the North China Craton: A Synoptic Overview. Gondwana Res. 2011, 20, 6-25. [CrossRef]

39. Zhai, M. Tectonic evolution of the north China craton. J. Geomech. 2019, 25, 722-745.

40. Zhang, Z.; Zhang, C.; Wang, S.; Liu, S.; Wang, L.; Du, S.; Song, Z.; Zhang, S.; Yang, E.; Chen, G.; et al. Views on Classification and Contrast of Tectonic Units in Strata in Shandong Province. Shandong Land Resour. 2014, 30, 1-23.

41. Yang, F.; Santosh, M.; Glorie, S.; Jepson, G.; Xue, F.; Kim, S.W. Meso-Cenozoic Multiple Exhumation in the Shandong Peninsula, Eastern North China Craton: Implications for Lithospheric Destruction. Lithos 2020, 370-371, 105597. [CrossRef]

42. Zhang, C.; Cui, F.; Zhang, Z.; Geng, R.; Song, M. Petrogenesis of Ore-Bearing Dioritic Pluton in Jinling Area in Western Shandong:Evidence from Zircon U-Pb Chronology and Petro-Geochemistry. Jilin Daxue Xuebao 2017, 47, 1732-1745. [CrossRef]

43. Reeves, C. Aeromagnetic Surveys: Principles, Practice and Interpretation; Geosoft: Toronto, ON, USA, 2005; Volume 155.

44. Hood, P. History of Aeromagnetic Surveying in Canada. Lead. Edge 2007, 26, 1384-1392. [CrossRef]

45. Noriega, G. Performance Measures in Aeromagnetic Compensation. Lead. Edge 2011, 30, 1122-1127. [CrossRef]

46. De Barros Camara, E.; Guimarães, S.N.P. Magnetic Airborne Survey-Geophysical Flight. Geosci. Instrum. Methods Data Syst. 2016, 5, 181-192. [CrossRef]

47. Zhao, G.; Han, Q.; Peng, X.; Zou, P.; Wang, H.; Du, C.; Wang, H.; Tong, X.; Li, Q.; Guo, H. An Aeromagnetic Compensation Method Based on a Multimodel for Mitigating Multicollinearity. Sensors 2019, 19, 2931. [CrossRef] [PubMed]

48. Riddihough, R.P. Diurnal Corrections to Magnetic Surveys-an Assessment of Errors. Geophys. Prospect. 1971, $19,551-567$. [CrossRef]

49. Whitham, K.; Niblett, E.R. The Diurnal Problem in Aeromagnetic Surveying in Canada. Geophysics 1961, 26, 211-228. [CrossRef]

50. International Association of Geomagnetism and Aeronomy. Division V-MOD Geomagnetic Field Modeling. Available online: https:/ / www.ngdc.noaa.gov/IAGA/vmod/index.html (accessed on 3 November 2020).

51. Thébault, E.; Finlay, C.C.; Beggan, C.D.; Alken, P.; Aubert, J.; Barrois, O.; Bertrand, F.; Bondar, T.; Boness, A.; Brocco, L.; et al. International Geomagnetic Reference Field: The 12th Generation. Earth Planets Sp. 2015, 67, 79. [CrossRef]

52. Evjen, H.M. The Place of the Vertical Gradient in Gravitational Interpretations. Geophysics 1936, 1. [CrossRef]

53. Peters, L.J. The Direct Approach to Magnetic Interpretation and Its Practical Application. Geophysics 1949, 14, 290-320. [CrossRef]

54. Bhattacharyya, B.K. Two-dimensional Harmonic Analysis as a Tool for Magnetic Interpretation. Geophysics 1965, 30, 829-857. [CrossRef]

55. Hood, P.; McClure, D.J. Gradient Measurements in Ground Magnetic Prospecting. Geophysics 1965, 30, 403-410. [CrossRef]

56. Cordell, L.; Grauch, V.J.S. Mapping Basement Magnetization Zones from Aeromagnetic Data in the San Juan Basin, New Mexico. In The Utility of Regional Gravity and Magnetic Anomaly Maps; Society of Exploration Geophysicists: Tulsa, OK, USA, 1985; pp. 181-197. ISBN 978-1-56080-272-3.

57. Blakely, R.J.; Simpson, R.W. Approximating Edges of Source Bodies from Magnetic or Gravity Anomalies. Geophysics 1986, 51, 26-31. [CrossRef]

58. Nabighian, M.N. The Analytic Signal of Two-Dimensional Magnetic Bodies with Polygonal Cross-Section: Its Properties and Use for Automated Anomaly Interpretation. Geophysics 1972, 37, 507-517. [CrossRef] 
59. Roest, W.R.; Verhoef, J.; Pilkington, M. Magnetic Interpretation Using the 3-D Analytic Signal. Geophysics 1992, 57, $116-125$. [CrossRef]

60. Miller, H.G.; Singh, V. Potential Field Tilt-A New Concept for Location of Potential Field Sources. J. Appl. Geophys. 1994, 32, 213-217. [CrossRef]

61. Verduzco, B.; Fairhead, J.D.; Green, C.M.; MacKenzie, C. New Insights into Magnetic Derivatives for Structural Mapping. Lead Edge 2004, 23, 16-119. [CrossRef]

62. Wijns, C.; Perez, C.; Kowalczyk, P. Theta Map: Edge Detection in Magnetic Data. Geophysics 2005, 70, 39-43. [CrossRef]

63. Ansari, A.H.; Alamdar, K. A New Edge Detection Method Based on the Analytic Signal of Tilt Angle (ASTA) for Magnetic and Gravity Anomalies. Trans. A Sci. 2011, 35, 81-88. [CrossRef]

64. Cooper, G.R. Reducing the Dependence of the Analytic Signal Amplitude of Aeromagnetic Data on the Source Vector Direction. Geophysics 2014, 79, 55-60. [CrossRef]

65. Wanyin, W.; Zhiyun, Q.; Yong, Y.; Weijiao, S. Some advances in the edge recognition of the potential field. Progress Geophys. 2010, 25, 196-210. [CrossRef]

66. Santos, D.F.; Silva, J.B.C.; Barbosa, V.C.F.; Braga, L.F.S. Deep-Pass-An Aeromagnetic Data Filter to Enhance Deep Features in Marginal Basins. Geophysics 2012, 77, J15-J22. [CrossRef]

67. Ma, G. Edge Detection of Potential Field Data Using Improved Local Phase Filter. Explor. Geophys. 2013, 44. [CrossRef]

68. Nasuti, Y.; Nasuti, A.; Moghadas, D. STDR: A Novel Approach for Enhancing and Edge Detection of Potential Field Data. Pure Appl. Geophys. 2019, 176, 827-841. [CrossRef]

69. Ying, G.-H.; Yao, C.-L.; Zheng, Y.-M.; Wang, J.-H.; Zhang, Y.-W. Comparative Study on Methods of Edge Enhancement of Magnetic Anomalies. Chin. J. Geophys. 2016, 59, 4383-4398. [CrossRef] 